\title{
Does Europe need the LHC?
}

\section{London}

SIR David Phillips, chairman of the Advisory Board for the Research Councils (ABRC), last week angered British physicists by questioning in public the need for a separate European programme in particle physics. His comments brought out into the open a long-running debate about whether the world needs two science projects costing thousands of millions of dollars each to address essentially the same question.

Speaking to the House of Lords Science and Technology Committee, Phillips said

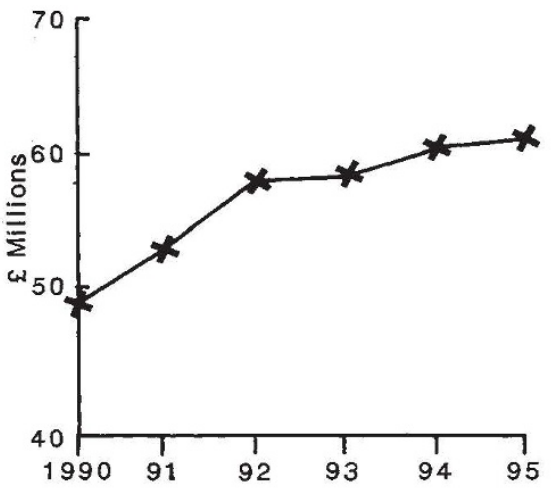

Phillips's headache - the planned UK subscription to CERN, 1990-95. Source: SERC.

that particle physics should be coordinated at a global level, but the "competitive spirit" of rival groups of physicists has won through. Science advisers in France and Germany, as well as in Britain, are concerned about the level of planned expenditure at CERN, the European particle physics laboratory in Geneva, Phillips said. The SFr 1730 million (about $£ 680$ million) cost of building a new accelerator, the Large Hadron Collider (LHC), is particularly worrying, he said, because the plan coincides with a similar US initiative - the $\$ 8,300$-million Superconducting Super Collider (SSC) project.

The British subscription to CERN, at more than $£ 50$ million a year, is the largest single component of the UK science budget. So, as he is chairman of the ABRC, which advises the Education and Science Secretary on the size and distribution of the science budget, Phillips' concern about future increases in the CERN subscription is understandable. But his comments come at a sensitive time: the CERN member nations must next year decide whether or not to go ahead with the LHC. Carlo Rubbia, director-general of CERN, last week declined to comment on the criticisms, preferring to let British physicists rally to CERN's cause.

CERN's supporters argue that if there is an undesirable overlap between the LHC and SSC projects, the fault lies with the United States. Sir William Mitchell, former chairman of the UK Science and Engineering Research Council (SERC), says that CERN and the British government were pushing hard for a world strategy in particle physics in the late 1980 s. But "it takes two to tango", he says - the United States was determined that the next stage in its particle physics programme would be a USdominated project. Sandy Donnachie, chairman of SERC's Nuclear Physics Board, which handles the UK CERN subscription, says the US attitude was: "we must regain the initiative from the Europeans". Nevertheless, Roy Schwitters, director of the SSC laboratory, responds that European physicists will be involved in experiments on the SSC, and are represented in his laboratory's peer review committees.

Mitchell, who is now president of CERN's governing council, believes the LHC project will not increase CERN's budget dramatically, as the new collider can be built around CERN's current centrepiece, the Large Electron-Positron collider, using some of the same equipment. Donnachie agrees: "if Europe were to buy into the SSC, it would finish up costing us more than the LHC."

Chris Llewellyn Smith, from the University of Oxford, says that competition between rival groups can be a spur to better science. He expects the LHC to be completed before the SSC, but says the LHC's greater versatility is in any case a powerful argument against simply pinning European hopes on a contribution to the SSC.

The primary function of both the SSC and the LHC is to collide two beams of protons. Proton collisions may yield the much sought after Higgs boson, predicted by current ideas in theoretical physics. The SSC will operate at a higher energy, but Llewellyn Smith says that greater intensity of the LHC proton beams should compensate for this, in part.

The LHC will also be able to operate as an electron-proton collider, providing the next step beyond the German HERA machine, where experiments start later this year. A third role is also planned, using the LHC to collide heavy ions. By forcing heavy nuclei

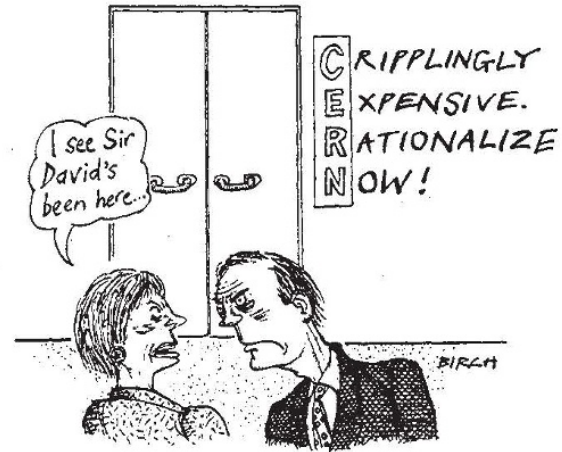

together, physicists may be able to duplicate the 'soup of quarks' that must have existed early in the evolution of the Universe, Llewellyn Smith says. A separate $\$ 300$-million US machine is planned to conduct similar experiments (but at a fraction of the energy the LHC will deliver) at the Brookhaven National Laboratory in New York State.

\section{Peter Aldhous}

\section{Smog alert in Kuwait City}

\section{London}

By concentrating on the large-scale environmental impact of the hundreds of oil-well fires now blazing in Kuwait (see Nature 350, 11; 7 March 1991), scientists and the media may have neglected a more immediate problem - the threat to public health in Kuwait posed by toxic fumes released into the atmosphere.

At present, plumes of smoke and fumes are rising rapidly into the atmosphere, so dangerous concentrations of toxic chemicals are not building up at ground level in populated areas. But David Shillito, from the consultant chemical engineers Cremer and Warner, fears that Kuwait City will face a serious air pollution problem in the coming months, as seasonal winds begin to blow. When the wind speed hovers around 12 metres per second, Shillito says, the smoke plumes will be "blown over", but will not disperse rapidly.

In June and early July, a prevailing wind known locally as the Shamal blows over the northern Kuwaiti oil fields towards the capital. Shillito, who worked in the Persian Gulf for many years, says that the air quality in Kuwait City may then be as bad as the infamous London smogs of the 1950s, for periods of $2-3$ days at a time. Oil-fire smoke contains a cocktail of noxious chemicals, from sulphur dioxide and other simple respiratory irritants, to carcinogens such as benzene and polyaromatic hydrocarbons.

Keith Browning, director of research at the UK Meteorological Office, says that his group has not been asked to extend its modelling of the environmental effects of the fires to assess in detail the likelihood of local air pollution events, but says that this "must represent a threat". Browning's group has considered the formation of ground-level ozone, by the action of sunlight on nitrogen oxides. Near the source of each fire, little light will penetrate the black smoke, but Browning says intermittent photochemical smogs are possible where the plumes fall back to the ground.

The Kuwaiti health ministry has asked the Geneva-based World Health Organization (WHO) for help in the aftermath of the war, and the air pollution threat is a top priority. WHO expects to announce this week that it is sending a team of clinical experts to Kuwait.

Another WHO concern is the serious risk of disease epidemics in Iraq, where allied bombing has caused severe disruption to water supplies and sanitation.

Peter Aldhous 